\title{
ELEMENTARY SCIENCE OR GENERAL SCIENCE?
}

\author{
By E. D. Huntington,
}

Normal School, Kalamazoo, Mich.

The essential difference between so-called elementary science and general science is that the former would present the elements of certain specialized sciences to the child from the standpoint of the sciences, while general science wotld select facts and principles from the whole field of science according to the needs of the ninth-grade child, and endeavor to present this subject matter to the child by such methods as will arouse and hold his interest. Elementary science would subject the child through successive semesters to the elements of physics, botany, zoology, physiology and hygiene, disguising those subjects under the titles of physical environment, plants, animals, and man. If chemistry were included, this elementary science sequence would represent a fairly ideal college cotirse in the sciences, which is to be telescoped and shoved down into the high school. But, no, it is already there. Are not these courses in physical environment, plants, animals, and man but our old-time friends, physics, botany, zoology, and physiology and hygiene that have already proved such failures in the high school?

In contrast, general science would analyze the needs of the ninth-grade child, and select such facts and principles from any and all branches of science as will fulfill these needs, and by grouping this subject matter about the facts of the pupil's everyday environment, endeavor to present this subject matter in such a way that the general principles of science will be associated in his mind as phenomena of his surroundings, and not as abstract definitions.

To date, the sciences have been unsuccessful in the high school, and there is an ever-growing tendency to change science courses from requirements to electives. Science now has the right of way in every field except the high and elementary schools; it is the basis of engineering, architecture, medicine; the courts base their decisions upon the testimony of science; the scientific method has entered business and commerce; and science is even now revolutionizing and unifying the various religious creeds. The newspapers and periodicals are crowded with facts and nearfacts of science; the general public is intensely interested in the discoveries and problems of science.

At such a time. it would seem that science would be the most 
interesting, the most popular, and the most useful of all the subjects in the high school curriculum; that it would constitute a great part of that curriculum and be required of all students. And yet in an age when our daily activities and commonest thoughts are determined by the precepts of science, we have awakened to find that the science group is a "weak sister" in the high school curriculum, and that to most students it is neither interesting nor profitable.

What is at fault? Is the failure of science due to a faulty selection and arrangement of subject matter, or to poor teaching? The general sience advocates hold that the failure is due primarily to the former, and that the subject matter itself has necessarily led to the poor teaching.

There has been little connection between the sciences as taught in the high school and the realities of life; to the child, botany, zoology, chemistry, and physics have each appeared as a heterogeneous mass of uninteresting and questionable facts, definitions, and rules, to be memorized and held in readiness for final exams. What he has taken away from these courses has been a hearty dislike for anything that bears the names of the individual sciences, especially botany and zoology.

The failure of the sciences in the secondary schools may be traced to two things-first, the ill-advised and so-called "logical" arrangement of the subject matter; and, second, the necessarily resulting arbitrary methods of the "forced feeding" of the unwholesome diet. Teachers of science have unconsciously in the past gone on the assumption that the division of the phenomena of nature into the highly differentiated sciences offers the proper classification under which to present those phenomena to the mind of a child. 'They forget that what is logical to the adult mind is often illogical to the child's mind, or even to the mind of the adult novice. Teachers have selected and arranged the subject matter of their science courses, not from the standpoint of the needs and interests of the child, but almost wholly from the standpoint of botany, zoology, physics, or chemistry. Naturally, the subjects so arranged have had little meaning for the child. To him, "There is no sense to it."

The second charge that the methods of teaching have been at fault brings on another storm of denial. "We point with pride" to our laboratory work, forgetting, or maybe not realizing, that a large part of the work-to many students, all of it-is merely what the overtaxed country school-teacher calls "busy work," 
and as such is not only of little value, but had better not be mentioned. Or we may "point with pride" to the splendid notebooks or examination papers that our pupils write for us. But when the student falls into the hands of an inquisitive parent, how soon is the illusion dispelled, and the whole process is proved to be a matter of vicious cramming, and not a matter understanding.

The above indictments will not be found true bills against every science course or the methods of every teacher. But just to the extent that a teacher is able to inculcate the principles of science into the understanding of the pupils, to that very extent does he draw upon the child's immediate experiences for his subject matter.

It is quite generally conceded, at least amongst science teachers, that there should be some course in science in the first year of high school, and to us the vital question is what particular science or what subject matter of science shall be selected. Botany, zoology, physics, physiography, and, of late, agriculture have all been tried and, unless presented by exceptionally skillful teachers, have been found wanting. Their failure may be quite correctly attributed to the fact that none of these subjects has proved of either much benefit or interest to the majority of students taking the course. In fact, these separate sciences have such a bad reputation that very few students enroll in the science courses except under comptision.

The ninth-grade pupil is making his first formal acquaintance with science at a time when his whole nature is crying out for general information about his daily environment. This diversity of interests and keen desire to know affords a splendid opportunity to acquaint him with the general principles and methods of science at a time when it will make the maximum impression on the individual.

What shall be our criteria for selecting the subject matter through which the child is to make his first formal acquaintance with science? Shall we select the subject matter from the standpoint of what will be of benefit and acceptable to the child at this point, or; shall our selection be determined by the classification of the specialized sciences and university requirements? Shall we select and arrange our subject matter so that it will appeal to the logic of the child, or to the logic of the advanced scientist?

If we decide in favor of the child, then our criteria must be, first. the needs of the child. and. second. his interests. 


\section{The Pupil's Needs.}

About thirty per cent of all the children who enter high school fail to return at the beginning of the second year, and so get no science training other than that which they may get in the one year. Many of the other students who continue through high school will take no further science courses unless required. Obviously, the science matter presented in this first year should be such that it will prove of maximum benefit to the individual throughout his life, and not be selected as a preparation for other science courses that are to follow. The pupil needs to become acquainted with the commonplace phenomena of his daily environment and acquire what scientific training and knowledge his immature mind will permit. The subject matter selected should be such that it will function in his daily life, and will lead to an understanding of his own body and his environment. The fundamental principles and facts of science generally, and not of some specialized branch of science, should constitute the subject matter of the science course at this point.

The sciences that are essentially fundamental are physics and chemistry. From a scientific standpoint, we must regard every phenomenon of the universe as a manifestation of physical and chemical laws - the atmosphere, earth, stars, plants, animals, and even life itself.

General science selects the elemental principles and facts of these fundamental sciences as the basis for its science course in the ninth grade, and seeks some group of everyday phenomena as a topic, the study of which will reveal the principles of science generally, and which will make the pupil realize that these principles are a part of his constant experience. The atmosphere serves admirably as such a topic, since it not only involves the fundamental principles of chemistry and physics, and leads directly into biological sciences, but it also holds the child's interest. It directly involves the mechanics of liquids and gases, heat and aqueous phenomena, density, electricity, and sound; and through the oxygen-carbon cycle, leads into the principles of physiology of both plants and animals. Respiration, oxidation, combustion, winds and rainfall, and health itself are among the more vital of the many aspects of this large topic, and when studied as such their close relationships are manifest.

The Pupil's Interests.

The classification of subject matter into our present-day sepa- 
rate sciences can be little understood, and even less appreciated by the immature students. Teachers generally experience difficulty in limiting the developing child's mind to one phase of the world of nature, such as botany, zoology, chemistry, or physics. The child is interested in the bearing that all the above-named subjects have on his experiences at a particular point, and can see no necessity for holding back certain knowledge of that topic until he takes another course in another science a year or two later, or never. The young child is interested in topics from all angles; he is not concerned with matter, energy, and space, with the periodic law, or with evolution as such. But he is already interested in the atmosphere, from a study of which he gains real conceptions of the fundamentals of physics, chemistry, physiography, and biology.

\section{Methods of Teaching.}

Too much of our science teaching has been a mere drill on the memorization of rules and definitions as stated in the textbooks; effective teaching of science must aim to have the child acquire a real understanding of the principles involved. But so long as the subject matter presented fails to interest the child and at the same time fails to appeal to his estimation of what is worth while, the teaching process will be the memorizing process, and the pupils will continue to say, "There's no sense to it."

The principles of science have been discovered by induction, and the teaching of science in the high school lends itself splendidly to the-same method. Let textbook assignment follow, and not precede, classroom discussion and experiment. With the inductive presentation, the child is led by question and experiment to discover facts and principles for himself, and they are memorized, if at all, only after they have been comprehended. The pupils are led to discover the problems, which gives the class a keen interest in the solution of them; new problems grow out of the solutions of the present problems, and the pupil's interest is held and his mind is alert to grasp the solution.

A common objection to the introduction of general science into the curriculum is the assertion that it is "wholly impossible to secure teachers for a subject so broad." Any teacher who knows enough chemistry and physics to efficiently teach botany, zoology, physiology, or physiography is sufficiently well prepared in those stbjects to-teach general science.

The advocates of general science hold that an appreciation of the general facts and principles of science is of far greater 
value to the individual, as represented by the average pupil, than is a detailed training in the facts and principles of one or two specialized sciences, and that to arbitrarily pick out those particular experiences that pertain only to a particular, specialized branch of science, while absolutely necessary for the advancement of science itself, it is out of place in the child's first and often only contact with science. Research in science and the teaching of science in the ninth grade have very little relation, and the classification of subject matter that leads to progress in the one field leads to stagnation in the other.

General science advocates would organize the sciences in the high school along the same lines that the courses in a particular science are organized in a university. When the university student begins his study of botany, his first course is not in morphology, cytology, ecology, taxonomy, or plant pathology. No, he must first take Botany I. General botany, if you please, must first be studied before he may attempt its specialized branches. Let us organize our high school science courses along these same lines; let the first course be an introductory course in general science. Science $I$, if you please, should be studied before the high school pupil attempts excursions into its specialized branches.

\section{STUDY OF EARLY FOSSILS.}

The fossil shells of the early invertebrates are of great importance to geologists, for they indicate the geologic period in which the rock beds containing them were formed-in otiner words, the age of the rock. Each fossiliferous rock bed contains characteristic forms or groups of forms that determine the period in which it was mud or sand. Former Director Powell of the United States. Geological Survey once tersely explained to a Congressional committee the value of paleontology by saying that it is "the geologist's clock," by which the tells the time in the world's history when any rock bed was formed.

The economic impcrtance of paleontology has been repeatedly shown in this country. In the earlier exploitation of anthracite coal, thousands of dollars were fruitlessly expended in New York in search of coal beds until the New York geologists showed that the beds in that state could contain no coal. The fossils in the New York rocks exploited are of Devonian age, whereas the fossils of the Pennsylvanian anthracite coal beds belong to the Carboniferous, a much later period. This discovery at once stopped a useless expenditure of money.

In times of doubt and perplexity, the geologist therefore turns to the paleontologist for light on the age and original order of the rock beds he is studying. The study of the animal and plant remains that are embedded in the rocks has thus become an important part of geologic work, and although the specialists who are engaged in this study are few, their work is of high importance. 